\title{
CommerGial SeGTion
}

\section{A MOVING WINDOW DISPLAY.*}

\section{(A Demonstration.)}

BY OTTO RAUBENHEIMER.

This is not a paper but merely a demonstration. Like many discoveries, mine was brought about quite accidentally by being one of the few phacmacists in the United States who make their own milk of magnesia, which can be prepared for thirty cents a gallon, instead of thirty-five cents per 12 -ounce bottle. ${ }^{1}$ In the process, I used a syphon to remove the wash water. On one occasion the rubber tubing contained a little pin-hole. To my great surprise this little leak produced a peculiar phenomenon, viz., air bubbles formed and were drawn down with the water, thereby producing a very striking effect.

This gave me an idea. I concluded to use this arrangement for a window display. In the rubber part of the original syphon, the little pin-hole got gradually larger and larger, until there was more air than water, and consequently the flow stopped. So I had to give the display up temporarily. I wondered how I could contrive to continue it, as it had proved quite an attraction. I found a way, and I have come here to show you just how it was done. The display was in my window for eighteen years and many people saw it. As the life of a patent is only seventeen years, I feel that I have kept the idea to myself long enough, and I am willing to part with it now for the benefit of the A. Ph. A. members, attending the Commercial Section at the Atlantic City Convention.

I have received inquiries about it from all over the United States. People wrote to me and asked me how it was done, and I told them that if they would come to Brooklyn I would show them.

All that it is necessary to use is a glass " $Y$ " tube, which can be bought for about fifteen cents. On one of the upper ends of the " $Y$ " tube I attach a short rubber hose, on which there is a metal screw compressor. This I can regulate by tightening it or gradually loosening it. This screw compressor costs twentyfive cents. The other upper end of the " $\mathrm{Y}$ " tube is connected with a piece of glass tubing which acts as the short leg of the syphon, namely, the one which sucks up the water. The lower end of the " $Y$ " tube is connected with a long glass tube, the long leg of the syphon, which is the water outlet. I had glass tubing going all over the window, but I could not bring it all. I merely brought a few pieces of tubing to demonstrate the way the apparatus works. The more glass tubing you have the more of an attraction the display will be. I ran the tubing over signs in the window, and also connected it with a Liebig condenser, used to demonstrate the distillation process.

I will now explain how I made the action continuous. To connect the pieces of glass tubing, I use rubber tubing. At the outlet I attach another screw com-

* Delivered before Section on Commercial Interests, Atlantic City meeting.

1 Proceedings A. Ph. A., Vol 55 (1907), p. 150. 
pressor to regulate the flow. The syphon is best started without admitting any air. The way it is regulated now, there is but very little air admitted. It shows up better when the liquid is not clear like water, but colored. By slightly opening the screw compressor on top, you will see that a little air enters and comes through along with the water, thereby forming air bubbles. The size of these can be regulated by admitting a little more or a little less air. In the same way, the outflow can be regulated by the screw compressor, so as to make the water and air run through more slowly or faster. The larger and long air bubbles with their convex ends very closely resemble hard gelatin capsules.

The display in my window frequently attracted so many people that the police had to come and drive them away. They were all guessing what made it go. I had the " $Y$ " tube high up in the window, so that it was concealed. When the water reservoir on top got empty, I would, of course, have to fill it again. Not wanting to be bothered with that, I connected it with a running stream of water by means of the faucet, which I turned so that the water would run in just as fast as it ran out. After that, I usually did not have to bother with it from the time I turned it on in the morning until night. I fixed it so that the bottle, which acted as the water reservoir, was about half full all the time. Of course, I had to keep my eye on it, as the water pressure sometimes varies.

I hope that this demonstration of a "Moving Window Display" will convince the members of the $\mathrm{A}$. $\mathrm{Ph}$. A. that even a little knowledge of physics and chemistry can be utilized to convince the public that your pharmacy is different from your neighbor's, who displays patent medicines, suspensories, dolls, or still worse, "apples."

\section{ABSTRACT OF DISCUSSION.}

J. B. Thомas: The manufacturers of soda drinks are using the same idea. Two colored men were standing before the window in which this was shown in connection with the soda water, and wondering at the mysterious disappearance of the water, one said, "Say, John, where do you suppose that is coming from?" The other replied, "It is not so important where it is coming from as where it is going to."

R. S. LEHMAN: This idea is being used for advertising purposes in the shape of a glass sign. There is one now in New York, which has been there quite a long time. There are letters, forming the words "Havana Cigars," which run in a continuous glass tube. The end of the word "Havana" joins the end of the word "Cigars." There is always a little globule of air around the letter.

CharLies H. LAWALL: I am wondering whether Dr. Raubenheimer ever had the experience of trying to syphon a liquid of lower density through one of higher. In a laboratory where I was once employed, we often had occasion to syphon liquids, and it was customary to fill the syphon with water before starting, and then immerse the syphon in the liquid to obtain the flow. On one occasion, chloroform was the liquid to be syphoned. The operator filled the syphon with water and immersed it in the chloroform. The chloroform came up to the top of the bend, but did not displace the water, but bubbles of chloroform went down through the water, just as the bubbles of air in the syphon of Dr. Raubenheimer.

Orro RAUBENHEmaR: That is a new experience; of course, air is a good deal cheaper than chloroform. 